\title{
6-18 ay arası çocuklarda beslenme alışkanlıkları ile anemi arasındaki ilişki ve bunların ebeveynlerinin eğitimi durumunun değerlendirilmesi
}

\section{The relationship between nutritional habits and anemia between 6-18 months in child and their parents' assessment of education}

\author{
Ahmet Güzelçiçek ${ }^{\mathbb{D}}$, Mahmut Demir ${ }^{(\mathbb{D}}$ \\ 1 Harran Üniversitesi Tıp Fakültesi Çocuk Sağıı̆ı ve Hastalıkları Anabilimdalı, Şanlıurfa, Türkiye
}

öz.

Amaç: Hastanemiz pediatri kliniğine başvuran rutin laboratuvar sonuçları sonrasında anemisi saptanan olguların sosyodemografik özellikleri ve beslenme öykülerinin, anemi laboratuvar tetkiklerine katkılarının olup olmadığının araşııııması amaçlanmış̧ır.

Materyal ve Metot: Mart - Kasım 2017 tarihleri arasında başvuran, yaşları $6-18$ ay arasında, rutin laboratuvar sonuçlarında anemisi saptanan 148 olgu çalışmaya alındı. Olguların ebeveynleri; eğitim durumları, ailenin gelir düzeyi, olguların; demografik bilgileri, anne sütü alım süreleri, mama ve ek gıdaya geçiş zamanları ile bu beslenmeye devam süreleri değerlendirildi.

Bulgular: Calısmaya 53 kız, 95'i erkek toplam 148 cocuk alındı. Annelerin; \%52,7'si babaların \%53,4'ü ilkokul mezunu; aile gelir seviyelerinin $\% 59,5$ olguda orta, $\% 37,8$ olguda düşük olduğu, olgularımızın $\% 94,6$ 'sının yaşamın ilk ayında anne sütü ile beslendiği, ancak yaşamın 6 . ayında bu oranın $\% 81,1^{\prime}$ 'ere, 12 . ayda $\% 44,6^{\prime}$ ya kadar gerilediği görüldü. Cinsiyet durumu dikkate alındığında erkek çocuklarda MCV ve ferritin, kız çocuklarda ise vitamin B12 seviyelerinin anlamlı derecede düšük olduğu saptandı. Ailelerin gelir düzeyleri ile hematolojik parametreler arasında fark saptanmadı. İlk 6 ayda anne sütü alan grup ile formül mamayla beslenen grup arasında istatistiksel açıdan anlamlı sekilde anne sütü alan grupta vitamin B12 düzeylerinde, mamayla beslenen gruptaysa ferritin düzeylerinde düşüklük saptanırken, bu iki grup arasında diğer laboratuvar parametreleri açısından fark saptanmadı.

Sonuç: Infant yaş grubunda beslenmenin incelenmesi ve Demir, B12 ve Folat gibi sık görülen vitamin eksiklikleri ile ilişkilendirilmesi, eksikliklere müdahale edilmesi ve toplumun bilinçlendirimesi ve farkındalık oluşturması açısından önemlidir.

Anahtar Kelimeler: Anemi, Beslenme, Anne sütü

Abstract

Background: The aim of this study was to investigate the sociodemographic characteristics and nutritional history of the patients with anemia after routine laboratory results in our pediatric clinic.

Methods: 148 patients who were admitted between March - November 2017, aged between 6-18 months and whose anemia was detected in routine laboratory results were included in the study. The parents of the cases; educational status, family income level, cases; demographic information, breastfeeding times, formula and transition to supplementary food and duration of feeding were evaluated.

Results: A total of 148 children (53 girls, 95 boys) were included in the study. Mothers; $52.7 \%$ of the fathers and $53.4 \%$ of them are primary school graduates; family income levels were moderate in $59.5 \%$, low in $37.8 \%, 94.6 \%$ of the cases were breastfed in the first month of life, but this rate was $81.1 \%$ in the 6th month of life It was observed that it decreased to $44.6 \%$. MCV and ferritin levels were significantly lower in boys and vitamin B12 levels were significantly lower in females. No difference was found between the income levels of the families and hematological parameters. In the first 6 months, there was a statistically significant decrease in vitamin B12 levels in the breastfed group and ferritin levels in the breastfed group, but no difference was found between these two groups in terms of other laboratory parameters.

Conclusion: It is important to investigate nutrition in infant age group and to associate it with common vitamin deficiencies such as Iron, B12 and Folate, to intervene in deficiencies and to raise awareness and raise awareness of the society.

Key Words: Anemia, Nutrition, Human milk

\section{Sorumlu Yazar I \\ Corresponding Author}

Dr. Ahmet Güzelçiçek

Harran Üniversitesi

Araştırma ve Uygulama Hastanesi

Osmanbey kampüsü.

63300 Şanlıurfa

Tel: +90 5058433963

E-mail: aguzelcicek@hotmail.com

Geliş tarihi / Received: 09/05/2019

Kabul tarihi / Accepted: 01/08/2019

HARRAN ÜNIVERSITESI

ULUSLARARASI MULTIDISIPLINER

ÇALIŞMALAR KONGRESI 8-10 Mart

2019, Şanlıurfa'da sözlü bildiri olarak sunulmuştur.

DOI: $10.35440 /$ hutfd. 562325 


\section{Giriş}

Anemi çocuklarda, adelosanlarda ve gebelerde yaygın olarak görülen önemli bir global halk sağlığı sorunudur. Dünyada anemi insidansı\% 22.9 - 26.7 arasındadır. Türkiye'de prevalans\% 40'ın üzerindedir (1). Aneminin nedenleri çoğul olmakla birlikte nutrisyonel ve enfeksiyonlar gibi birçok nedene bağlı oluşabilmektedir. Sıklıkla nutrisyonel ve nutrisyonel olmayan nedenlerin birlikteliği ile meydana geldiği görülmektedir (2). Dünya çapında aneminin en sık görülen nedeninin demir eksikliği olduğu görülmüştür. Toplumların refah seviyesi ile doğru orantılı olarak demir eksikliği anemisinin görülme sıklığı değişmektedir (2). Diyetin demirden fakir olması sonucu gelişen nutrisyonel eksiklik ve hızlı büyüme demir eksikliği anemisinin en sık nedenidir. İlk 6 ay anne sütü ile beslenen ve 6 . aydan itibaren uygun ek besinlere başlanan süt çocuklarında demir eksikliği anemisi daha az görüldüğü bildirilmiştir (5). Bebeklik döneminde hafif demir eksikliğinin daha sonraki bilişsel yetersizliklerle ilişkili olabileceği hakkında artan miktarda kanıt bulunmaktadır (4). Gelişmekte olan ülkelerde aneminin en sık nedeni demir eksikliği anemisi olmasına rağmen, anemilerin bir kısmı $B_{12}$ vitamini ve folat eksikliği nedeniyle meydana gelebilir. Bu vitaminlerin eksiklikleri çoğunlukla demir eksikliği ile beraber görülebilir (2). Bu nedenle infant yaş grubunda beslenmenin incelenmesi ve Demir, B12 ve Folat gibi sık görülen vitamin eksiklikleri ile ilişkilendirilmesi, eksikliklere müdahale edilmesi ve toplumun bilinçlendirilmesi açısından önemlidir.

\section{Materyal ve Metot}

Çalışma Mart 2017 - Kasım 2017 tarihlari arasında Harran Üniversitesi Tıp Fakültesi Araştırma ve Uygulama Hastanesi Çocuk Bölümüne başvuran ve yaşları 6-18 ay arasında değişen ve anemisi saptanan 148 çocuk çalışmaya alındı. Kliniğimize herhangi bir neden ile başvuran ve ön tanılarında anemi saptanan hastalarda rutin olarak yapımış olan laboratuvar sonuçları kayıttı klinik bulguları ile birlikte retrospektif olarak değerlendirildi. Olguların ebeveynleri eğitim durumları (okuma yazması yok, ilkokul, ortaokul, lise, yüksek okul) ailenin gelir düzeyi (0 - 2000 TL, 2000 3500 TL, 3500 - 5000TL, >5000), olgular ise; demografik (yaş, cinsiyet ve kardeş sayısı) bilgileri, anne sütüne başlama yaşları ve anne sütü alım süreleri, mama ve ek gıdaya (Serbest Besin; yoğurt, meyve sular, yemek suları, çorba, bisküvi, pirinç unu, nişasta, inek sütü vd.) geçiş zamanları ile bu beslenmeye devam süreleri aylık skalalar ile değerlendirildi. Olguların ağırlık ve boy persentilleri ise; 2008'de revize edilerek yayınlanan ve ülkemizde rutin olarak Türk çocuklarında kullanılan vücut ağırlığı, boy uzunluğu, baş çevresi ve vücut kitle indeksi referans değerleri baz alınarak hesaplandı. Tüm hastaların sosyodemografik özellikleri, beslenme bilgileri ve mevcut laboratuvar parametrelerine ait veriler önceden hazırladığımız formlara işlendi. Daha sonra bu verilerin istatistiksel analizi yapııdı, ortaya çıkan sonuçlar değerlendirildi.

Etik Onay: Bu çalışma için etik onayı Harran Üniversitesi Girişimsel Olmayan Klinik Araştırmalar 05.11.2018 tarihli 11 nolu oturumun ve 08-09-16 nolu kararı ile Etik Kurulu 'ndan alındı.

İstatistiksel Analiz Yöntemleri Verilerin istatistiksel analizinde SPSS 22,0 paket programı kullanıldı. Kategorik ölçümler sayı ve yüzde olarak, sayısal ölçümler ise Ortalama ve Standart Sapma (ve gerekli yerlerde minimum-maksimum) olarak özetlendi. Kategorik ölçümlerin DEA olan ve olmayan gruplar arasında karşılaştırılmasında Ki Kare test istatistiği kullanıldı. Sayısal ölçümlerin karşılaştııımasında ise Mann Whitney-U testi kullanıldı. Tüm testler de istatistiksel önem düzeyi ise; $(p<0,05)$ olarak alındı.

\section{Bulgular}

Çalışmaya alınan toplam olgu sayısı 148 olup bu olguların $53(\% 35,8)$ 'ü kız, 95 (\%64,2)'i erkek idi. Olguların yaşları; Ortalama \pm Standart Sapma (SD), Medyan (Min -Maks) olacak şekilde; $12,9 \pm 3,2,13,0$ (6-18) ay olarak saptandı. Çalışmaya alınan tüm olguların laboratuvar özellikleri incelendi ve bu parametrelerin değerleri Tablo 5 'da sunuldu. Cinsiyet durumu dikkate alındığında MCV, Vitamin B12 ve Ferritin seviyeleri arasında fark olduğu görüldü. Erkek çocuklarında Ferritin ve MCV düzeylerinin, kızlarda ise Vitamin B12 düzeyinin düşük $(p<0,05)$ olduğu saptandı. Buna karşın diğer parametreler açısından fark saptanmadı $(p$ $>0,05$ )

Çalışmaya alınan olguların annelerinin yaşları; $26,4 \pm 4,7$, 26,0 (18 - 40) yıl olup, $146(\% 98,6)$ 'sının annesi ev hanımı iken, sadece $2(\% 1,4)$ olgunun annesinin çalıştı̆̆ını saptandı. Ebeveynlerin eğitim seviyeleri incelendiğinde ise; 29 $(\% 19,6)$ annenin okuma yazma bilmediği, $78 \quad(\%$ $52,7)$ 'unun ilkokul, $22(\% 14,9)$ 'sinin ortaokul, 17 (\%11,5)' sinin lise ve $2(\% 1,4)$ 'sinin ise yüksekokul mezunu olduğu, ayrıca olguların babaları değerlendirildiğinde 5 (\% $10,1)$ 'inin okuma yazma bilmediği, $79(\% 53,4)$ 'unun ilkokul, 22 (\% 14,9)'sinin ortaokul, 29 (\% 19,6)'unun lise ve 3 (\% 2,0 )'ünün ise yüksekokul mezunu olduğu tespit edildi (Tablo 2).

Olgularımızın aile gelir seviyelerine bakıldığında 56 $(\% 37,8)$ ailenin düşük, $88(\% 59,5)$ ailenin orta, $4(\% 2,7)$ ailenin ise yüksek gelir düzeyine sahip olduğu saptandı. Aile gelir düzeyleri ile ölçülen laboratuvar parametreleri arasında fark saptanmadı $(p>0,05)$, (Tablo 3 ).

Çalışmaya alınan tüm olguların ağırlık ve boy persentil dağılım verileri Tablo 4'de sunuldu.

Çalışmaya alınan tüm olguların doğumdan itibaren aylık periyotlarına göre ilk 12 aylık süredeki anne sütü, mama ve serbest besin kullanım durumları Tablo 6'de sunulmuştur. 0-6 ay boyunca anne sütü ağırlıklı beslenen ve beslenmeyen grupların laboratuvar parametreleri karşılaştııldığında, vitamin B12 düzeyi formül mama ile beslenenlerde yüksek iken, ferritin düzeyi ise anne sütü alanlarda anlamlı 
bir şekilde yüksek olduğu saptandı(p 0,05), (Tablo 7).

Tablo 1. Cinsiyet Durumuna Göre Laboratuvar Değerleri Karşıllaştırma Sonuçları

\begin{tabular}{lccc}
\hline \multicolumn{4}{c}{ Cinsiyet Durumuna Göre Laboratuvar Değerleri Karşılaştırma Sonuçları } \\
\hline Cinsiyet & Kı & Erkek & \\
\hline $\mathbf{n}(\%)$ & $\mathbf{5 3}(\% 35,8)$ & $\mathbf{9 5}(\% \mathbf{6 4 , 2})$ & $\mathbf{P}$ \\
\hline Laboratuvar parametreleri & Sonuçlar & Sonuçlar & $>0,05$ \\
\hline $\mathrm{Hb}(\mathrm{g} / \mathrm{dL})$ & $9,4 \pm 1,3,9,9(4,8-10,9)$ & $9,5 \pm 1,2,9,9(5,6-10,9)$ & $>0,05$ \\
Folat $(\mathrm{ng} / \mathrm{ml})$ & $11,1 \pm 3,9,10,6(4,5-18,4)$ & $11,1 \pm 4,1,11,1(4,2-22)$ & $<0,05$ \\
Ferritin (ng/mL) & $22,0 \pm 5,3,7,5(0,8-301)$ & $8,3 \pm 1,8,6(0-188)$ & $>0,05$ \\
Platelet (10'3/uL) & $343 \pm 125,336(100-611)$ & $382 \pm 142,367(108-702)$ & $<0,05$ \\
Vit B12 (pg/mL) & $324 \pm 183,280(47-856)$ & $403 \pm 200,382(51-987)$ & $<0,05$ \\
MCV (fL) & $68,9 \pm 13,2,67(51,8-113,8)$ & $63,1 \pm 7,1,63,8(49,6-96,29$ & $<0$ \\
RDW (\%) & $19,3 \pm 4,1,17,9(16,1-35,4)$ & $20,0 \pm 4,7,18,6(16,1-43,7)$ & $>0,05$ \\
\hline${ }^{*}$ Ortalama $\pm S D$, Medyan (Min-Maks) & & &
\end{tabular}

Tablo 2. Çalışmaya Alınan Olguların Ebeveynlerinin Eğitim Seviyeleri

\begin{tabular}{lll}
\hline Eğitim durumları & Anne & Baba \\
\hline Okuma Yazma Bilmeyen & $29(\% 19,6)$ & $15(\% 10,1)$ \\
Illkokul Mezunu & $78(\% 52,7)$ & $79(\% 53,4)$ \\
Ortaokul Mezunu & $22(\% 14,9)$ & $22(\% 14,9)$ \\
Lise Mezunu & $17(\% 11,5)$ & $29(\% 19,6)$ \\
Yüksekokul Mezunu & $2(\% 1,4)$ & $3(\% 2,0$ \\
\hline
\end{tabular}

Tablo 3. Olguların Aile Gelir Düzeyi ve Laboratuvar Parametreleri Arasındaki ilişki

\begin{tabular}{lllll}
\hline & Düşük & Orta & Yüksek & P \\
\hline & $56(\% 37,8)^{* *}$ & $88(\% 59,5)^{\star *}$ & $4(\% 2,7)^{\star *}$ & \\
Hb* $^{*}$ & $9,2 \pm 1,5(4,8-10,9)$ & $9,6 \pm 1,1(5,6-10,9)$ & $9,3 \pm 1,6,9,6(7,3-10,7)$ & $>0,05$ \\
MCV* $^{*}$ & $64,8 \pm 11,5(49,6-111,8)$ & $65,6 \pm 9,3(50,6-113,, 8)$ & $62,9 \pm 5,9(57,1-68,2)$ & $>0,05$ \\
Platelet $^{*}$ & $381 \pm 205(148-702)$ & $362 \pm 143(100-693)$ & $333 \pm 172(146-488)$ & $>0,05$ \\
Vit B12* $^{*}$ & $370 \pm 205,376(47-987)$ & $374 \pm 199(51-974)$ & $442 \pm 33,4(393-468)$ & $>0,05$ \\
Folat* $^{*}$ & $11,2 \pm 4,3,11,2(4,5-21)$ & $11,1 \pm 3,9,10,7(4,2-22)$ & $9,9 \pm 2,4,10,5(6,6-12,1)$ & $>0,05$ \\
Ferritin* $^{*}$ & $14,9 \pm 4,6,6,1(0,0-301)$ & $12,6 \pm 3,1,6,4(1,3-227)$ & $5,5 \pm 3,9,5,0(2,2-9,9)$ & $>0,05$ \\
RDW* $^{*}$ & $20,1 \pm 4,7(16,1-35,4)$ & $19,5 \pm 4,0(16,1-43,7)$ & $19,4 \pm 1,7(17,7-21,3)$ & $>0,05$ \\
\hline
\end{tabular}

${ }^{*}$ Ortalama \pm SD, Medyan (Min-Maks), ${ }^{*} n(\%)$

Tablo 4. Çalışmaya Alınan Tüm Olguların Ağırıı ve Boy Persentil Dağılımları

\begin{tabular}{lll}
\hline Persentil Değeri & Ağırlık $\mathbf{n}(\%)$ & Boy $\mathbf{n}(\%)$ \\
\hline $\mathbf{3} \mathbf{p}$ altı & $20(\% 13,5)$ & $21(\% 14,2)$ \\
$\mathbf{3 - 1 0} \mathbf{p}$ & $23(\% 15,5)$ & $7(\% 4,7)$ \\
$\mathbf{1 0 - 2 5} \mathrm{p}$ & $25(\% 16,9)$ & $13(\% 8,8)$ \\
$\mathbf{2 5 - 5 0} \mathbf{p}$ & $42(\% 28,4)$ & $38(\% 25,7)$ \\
$\mathbf{5 0 - 7 5} \mathrm{p}$ & $16(\% 10,8)$ & $34(\% 23,0)$ \\
$\mathbf{7 5 - 9 0} \mathrm{p}$ & $10(\% 6,8)$ & $22(\% 14,9)$ \\
$\mathbf{9 0 - 9 7} \mathbf{p}$ & $4(\% 2,7)$ & $9(\% 6,1)$ \\
$\mathbf{9 7}$ p üstü & $8(\% 5,4)$ & $4(\% 2,7)$ \\
\hline
\end{tabular}


Tablo 5. Tüm Olguların Laboratuvar Özellikleri

\begin{tabular}{ll}
\hline Parametreler & Düzey \\
\hline $\mathrm{Hb}(\mathrm{g} / \mathrm{dL})^{\star}$ & $9,4 \pm 1,3(7,8-10,9)$ \\
Ferritin $(\mathrm{ng} / \mathrm{mL})^{*}$ & $13,3 \pm 35,6(0-301)$ \\
Folat $(\mathrm{ng} / \mathrm{ml})^{*}$ & $11,1 \pm 4,0(4,2-22,0)$ \\
Vit B12 $(\mathrm{pg} / \mathrm{mL})^{\star}$ & $374,4 \pm 197,1(47-987)$ \\
Platelet $\left(10^{\prime} 3 / \mathrm{uL}\right)^{\star}$ & $368 \pm 137(100-702)$ \\
$\mathrm{MCV}(\mathrm{f} \mathrm{L})^{*}$ & $65,2 \pm 10,1(49,6-113,8)$ \\
$\mathrm{RDW}(\%)^{*}$ & $19,7 \pm 4,2(16,1-43,7)$ \\
\hline
\end{tabular}

*Ortalama \pm SD (Min-Maks)

Tablo 6. Çalışmaya Alınan Olguların Doğumdan İtibaren Anne Sütü, Mama ve Serbest Besin Kullanım Durumları

\begin{tabular}{ccccccc}
\hline \multicolumn{2}{c}{ Anne sütü } & \multicolumn{2}{c}{ Formül mama } & \multicolumn{2}{c}{ Ek besin } \\
\hline $\begin{array}{c}\text { Süre } \\
\text { (ay) }\end{array}$ & Alan & Almayan & Alan & Almayan & Alan & Almayan \\
\hline 1. & $140(\% 94.6)$ & $8(\% 5,40)$ & $23(\% 15,5)$ & $125(\% 84,5)$ & $0(\% 0)$ & $148(\% 100)$ \\
2. & $136(\% 91,9)$ & $12(\% 9,10)$ & $26(\% 17,6)$ & $122(\% 82,4)$ & $0(\% 0)$ & $148(\% 100)$ \\
3. & $134(\% 90.5)$ & $14(\% 9.5)$ & $30(\% 20.3)$ & $118(\% 79.7)$ & $2(\% 1.4)$ & $146(\% 98.6)$ \\
4. & $130(\% 87.8)$ & $18(\% 12.2)$ & $31(\% 20.9)$ & $117(\% 79.1)$ & $13(\% 8.8)$ & $135(\% 91.2)$ \\
5. & $126(\% 85,1)$ & $22(\% 14,9)$ & $30(\% 20.3)$ & $118(\% 79.7)$ & $29(\% 19.6)$ & $119(\% 80.4)$ \\
6. & $120(\% 81.1)$ & $28(\% 18.9)$ & $37(\% 25.0)$ & $111(\% 75)$ & $63(\% 42.6)$ & $85(\% 57.4)$ \\
7. & $112(\% 75.6)$ & $36(\% 24.4)$ & $35(\% 23.7)$ & $113(\% 76.3)$ & $103(\% 69.5)$ & $45(\% 30.5)$ \\
8. & $102(\% 68.9)$ & $46(\% 31.1)$ & $38(\% 25.6)$ & $110(\% 74.4)$ & $118(\% 79.7)$ & $30(\% 20.3)$ \\
9. & $92(\% 62.1)$ & $56(\% 37.9)$ & $47(\% 31.8)$ & $101(\% 68.2)$ & $125(\% 84.4)$ & $23(\% 15.6)$ \\
10. & $83(\% 56.1)$ & $65(\% 43.9)$ & $53(35.8)$ & $95(\% 64.2)$ & $139(\% 99.04)$ & $9(\% 0.06)$ \\
11. & $72(\% 48.4)$ & $76(\% 51.6)$ & $58(\% 39.1)$ & $90(\% 60.9)$ & $148(\% 100)$ & $0(\% 0)$ \\
12. & $65(\% 43.9)$ & $83(\% 56.1)$ & $60(\% 40.5)$ & $88(\% 59.5)$ & $148(\% 100)$ & $0(\% 0)$ \\
\hline
\end{tabular}

Tablo 7. 0-6 Ay Anne Sütü ile Beslenen ve Mama Ağırlıklı Beslenen Tüm Gruplardaki Laboratuvar Parametreleri

\begin{tabular}{lllc}
\hline \multicolumn{3}{c}{ Beslenme şekli (0-6 ay) } & P \\
\hline Parametreler & Anne sütü & Formül mama ağırlıklı & $>0.05$ \\
\hline $\mathrm{Hb}$ & $9,5 \pm 1,3(7,8-10,9)$ & $9,7 \pm 1,0(6,5-10,8)$ & $>0.05$ \\
MCV & $66 \pm 10,6(49,6-113,8)$ & $63,5 \pm 5,7(51-69,9)$ & $>0.05$ \\
RDW & $19,6 \pm 3,7(16,1-35,4)$ & $18,4 \pm 3,2(16,1-30,6)$ & $>0.05$ \\
Platelet & $369 \pm 141(100-702)$ & $361 \pm 144(123-702)$ & $>0.05$ \\
Folat & $11,3 \pm 4,0(4,2-22,9)$ & $10,7 \pm 3,9(4,6-20,0)$ & $<0.05$ \\
Vit B12 & $338 \pm 177(47-931)$ & $481 \pm 195(192-974)$ & $<0.05$ \\
Ferritin & $14,8 \pm 3,9(7,0-301)$ & $6,7 \pm 2,9(1,3-11,9)$ & \\
\hline
\end{tabular}

*Ortalama \pm SD (min-maks)

\section{Tartışma}

Anemi, birey, aile ve toplum için ciddi bir halk sağlığı sorunudur. Ülkelerin gelişimi ve anemi sıklığı birbiriyle ilişkilidir. Anemi gelişmekte olan ülkelerde toplumun yaklaşık yarısını etkiler. Beş yaşın alıındaki çocuklar, hızlı büyüme ve gelişme nedeniyle özellikle risk altındadır (5). WHO anemi raporuna göre, Türkiye'deki okul öncesi çocuklar da anemi prevalansının \% 32,6 olduğu ve bu nedenle de ülkemizin anemi açısından orta seviyede bir halk sağlığı sorunu olan ülkelerden biri kategorisinde olduğu bildirilmiştir(6). Türkiye'de, Kıııçbay ve ark.(7) 0-19 yaş arası tüm çocukluk yaş grubu için genel anemi prevalansını; \% 31, Taşyenen ve ark. (8) \% 44, Çetin ve ark.(9) \% 44,3, Eren ve ark. (10) \% 45,6 ve Oğuz ve ark.(11) \% 49,6 olarak bildirmişlerdir. Gelişmekte olan ülkelerde aneminin en sık nedeni demir eksikliği anemisi olmasına rağmen, anemilerin önemli bir kısmı da B12 vitamini ve Folat eksikliği nedeniyle meydana gelmektedir. Bu vitaminlerin eksiklikleri çoğunlukla demir eksikliği ile beraber görüldüğü için salt olarak bu vitaminlerin eksikliklerine bağlı anemilerin prevelansını kesin olarak saptanmak oldukça zordur (2). Dömellof ve ark.(12) cinsiyet ile demir durumu ilişkisini incelemek üzere anne sütü ile beslenen 263 süt çocuğunda yaptıkları çalışmalarında 
dördüncü aydan sonra rastlantısal olarak plasebo ve ek demir verilen süt çocukların da 4'üncü, 6' Incı ve 9'uncu aylardaki, $\mathrm{Hb}, \mathrm{MCV}$ ve Ferritin değerlerini incelediklerinde, bu değerlerin erkek çocuklarda kız çocuklarına göre anlamlı olarak düşük saptadıklarını bildirmişlerdir. Benzer bir çaIışma da ülkemizde, Bülbül L. ve ark.(13) tarafından yapılmış olup bu çalışmada yaşları 6 - 41 ay arasında değişen 650 çocuğun $\mathrm{Hb}$, Htc, MCV değerleri incelenmiş ve ortalama $\mathrm{Hb}$, Htc ve MCV değerlerinin kız çocukların da erkek çocuklara göre yüksek olduğu rapor etmişlerdir. Schneider ve ark. (14) Kaliforniya'da yapılan bir çalışmada, düşük gelirli ailelerin 12-36 aylık çocuklarının anemi için risk faktörlerini değerlendirdiğini; demir eksikliği, erkeklerde kadınlardan anlamlı olarak yüksek bulundu. Bu çalışmaya benzer olsa da parametreleri açısından farklılık gösteren çalışmamızda cinsiyeti dikkate alarak yaptığımız karşılaştırmada erkek çocuklarında Ferritin ve MCV düzeylerinin, kızlarda ise Vitamin B12 düzeyinin düşük $(p<0,05)$ olduğu saptandı, ancak diğer hematolojik parametreler ve Folat açısından ise erkek ve kızlar arasında fark saptanmadı $(p>0,05)$. Erkeklerde aneminin daha sık görülmesinin nedeni, yüksek büyüme oranlarından kaynaklanmaktadır (15). Bölgemiz düşük sosyoekonomik bir bölge konumundadır, bu nedenle kliniğimize başvuran hastalarımızın da sosyoekonomik göstergeleri oldukça düşük seviyelerdedir. Bölgemizin bu özelliğinin çalışmamıza yansıyacağını öngörmemize karşın, çalışmamızda aile gelir düzeyleri ile anemi tanısı için ölçülen laboratuvar parametreleri arasında fark saptanmadı $(p>0,05)$. Bu sonuçlar Bülbül L. ve ark.(13) yaşları 6 - 41 ay arasında değişen 650 çocukta yaptıkları çalışmadaki sonuçlara benzer idi. Bu sonuç sağlık bakanlığının aile sağ ığı merkezlerinde uyguladığı demir proflaksisinin bir sonucu olduğu kanaatindeyiz. Çalışmadaki olguların persentil dağılımlarına baktığımızda belirgin bir anormalliğe rastlamadık. Duncan ve ark. (16) 6 ay sadece anne sütü ile beslenen bebeklerde $\mathrm{Hb}, \mathrm{MCV}$ ve Ferritin düzeylerini değerlendirdikleri çalışmalarında hiçbir olguda demir eksikliğine rastlamadıklarını bildirmişlerdir. Vatandaş ve ark. (17) ise; ilk 6 ay sadece anne sütü veya anne sütü + mama veya sadece mama ile beslenen 3 gruplu çalışmalarında gruplardaki bebeklerin $\mathrm{Hb}$ konsantrasyonları arasında fark olmadığını bildirmişlerdir. Çalışmamızda da anne sütü almayan grubu; 0-6 ay aylık süre boyunca mama + serbest beslenme ile beslenen grup olarak tanımladık ve 0-6 ay boyunca anne sütü alan grup ile almayan grupları karşılaştırdığımızda iki grup arasında Vitamin B12 ve Ferritin seviyeleri açısından fark $(p<0,05)$ olduğunu ve bu farkın ise anne sütü alan grupta Vitamin B12 düzeylerinde, mama ağırıklı beslenen grupta ise Ferritin düzeyindeki düşüklük şeklinde olduğunu saptadık. Ancak bu iki grup arasında diğer laboratuvar parametreleri açısından herhangi bir farklıı̆ga rastlanmadı $(p>0,05)$. Anne sütü alan grupta normal olduğu düşünülen ferritinin ise anne sü- tündeki demirin yüksek emiliminden kaynaklandığını düşünmekteyiz. 0-12 ay boyunca anne sütü ağırlıklı beslenen ve mama ağırlıkı beslenen gruplar karşılaştırıldığında Vitamin B12 seviyeleri açısından fark olduğu saptandı ( $p$ $<0,05$ ), anne sütü ağırlıklı beslenen olgularda Vitamin B12 seviyeleri, 0-6 aylık olgularda olduğu gibi düşük idi. Buna karşın diğer laboratuvar parametreleri açısından her iki grup arasında herhangi bir fark saptanmadı $(p>0,05)$. ÇaIışmamıza katılan hiçbir vakada folat eksikliğine rastlanmadı. Bu veriler ışığında 6 - 18 ay arası çocuklarda Folat durumunun anne sütü, mama ile beslenme veya serbest beslenme ile ilişkili olmadığı sonucuna vardık.

Sonuç olarak; infant yaş grubunda beslenmenin incelenmesi ve Demir, B12 ve Folat gibi sık görülen vitamin eksiklikleri ile ilişkilendirilmesi, eksikliklere müdahale edilmesi ve toplumun bilinçlendirilmesi açısından önemlidir. Anemi açısından, çocukları eğitmek, uygun yaş gruplarında tarama yapmak ve risk altındaki çocuklar için demir ve vitamin takviyesi uygulamak uygun olacaktır. Gerek anne sütü alan ve gerekse karışık beslenen tüm olgularımızda düşük olarak saptadığımız Vitamin B12 düzeylerindeki bu düşüklüğün ise anne beslenmesinden kaynaklandığını, ülkelerin ekonomik koşullarının düzeltilmesi ile beslenme sorunlarının da düzeleceği ve bu sorunun üstesinden gelineceğine inancımız tamdır.

\section{Kaynaklar}

1. Akca SO, Bostanci MÖ. The impact of anemia and body mass index (BMI) on neuromotor development of preschool children. Rev Assoc Med Bras. 2017;63(9):779-86.

2. Mannar MGV. The economics of addressing nutritional anemia. In: Zimmermann MB, Kraemer K, Ed.The Guidebook Nutritional Anemia, 2007;13-15

3. Karakaş Z, Ağaoğlu L. Anemiler. In: Neyzi O, Ertuğrul T. Pediatri Cilt 2. İzmir: Nobel Tıp Kitabevleri. 2010;1285-1311

4. Gedikoğlu G. Ağaoğlu L. Kan Hastalıkları. In: Neyzi O, Ertuğrul T. Pediatri. Cilt 2. 2.B. İzmir: Nobel Tıp Kitapevleri; 1993; 347-63.

5. Lisboa MBMC, Oliveira EO, Lamounier JA, Silva CAM, Freitas RN. Prevalence of irondeficiency anemia in children aged less than 60 months: A population-based study from the state of Minas Gerais, Brazil. Rev Nutr. 2015;28(2):121-31.

6. Benoist B. McLean E. Egli I. National estimates of anaemia In. Worldwide prevalence of anaemia Guidebook, WHO Global Database On Anemia. 1993-2005; 44-51

7. Kılıçbay F, Güneş AM, İlçöy YÖ. Bursa İlinde 1-16 Yaş Arası Çocuklarda Demir Eksikliği ve Demir Eksikliği Anemisi Prevalansı. Güncel Pediatri Dergisi 2006; 3: 59

8. Taşyenen Vü. Manisa Yöresinde Demir Eksikliği Anemi Prevalansı ve Demir Eksikliği Anemisinde Tarama Testi Olarak Hemogram, RDW, Ferritin Kullanımı. Uzmanlık Tezi, Celal Bayar Üniversitesi Çocuk Sağlığı ve Hastalıkları Anabilimdalı, Manisa/Türkiye, 2006

9. Aydın A, Çetin E. İstanbul'da Yaşayan Çocuk ve Adolesanlarda Anemi Prevalansı ve Anemilerin Morfolojik Dağılımı: Çocukların Yaş, Cinsiyet ve Beslenme Durumu İle Anne-Babaların Ekonomik ve Öğrenim Durumunun Anemi Prevalansı Üzerine Etkileri, Türk Pediatri Arşivi, 1999; 34: 11-13

10. Eren EÇ. Çocuklarda Yaş Gruplarına ve Cinslere göre Anemi ve Demir Eksikliği Anemisi Sıklığının İncelenmesi. Uzmanlık Tezi, 
Bakırköy Sadi Konuk Eğitim ve Araştırma Hastanesi, İstanbul/Türkiye, 2008

11. Oğuz F, Uzunhan T, Binnetoğlu F. Hipokrom Mikrositer Anemide Demir Eksikliği Anemisi ve Talasemi Taşıyıclığı Oranları. Çocuk Dergisi 2009; 9(3):116-122

12. Domellof M, Dewey KG, Lonnerdal B. et al. The diagnostic criteria for iron deficiency in infants should be reevaluated. J Nutr 2002;132: 3680-6.

13. Bülbül L, Baysal SU, Gökçay G. ve ark. Altı aylık süt çocuklarında yalnız anne sütü ile beslenme süresi ile kan hemoglobin düzeyi ve eritrosit indeksleri ilişkisi. İstanbul Üniversitesi Tıp Fakültesi. Türk Ped Arşivi 2008; 43: 119-26.

14. . Schneider JM, Fujii ML, Lamp CL, Lönnerdal B, Dewey KG, Zidenberg-Cherr $\mathrm{S}$. The use of multiple logistic regression to identify risk factors associated with anemia and iron deficiency in a convenience sample of 12-36-mo-old children from low-income families. Am J Clin Nutr. 2008;87(3):614-20.

15. Zuffo CR, Osório MM, Taconeli CA, Schmidt ST, da Silva BH, Almeida CC. Prevalence and risk factors of anemia in children. J Pediatr (Rio J). 2016;92(4):353-60.

16. Duncan B, Schifman RB, Corrigan JJ, Schaefe C. Iron and the exclusively breast-fed infant from birth to six months. J Pediatr Gastroenterol Nutr 1985; 4: 421-425.

17. Vatandaş N, Atay G, Tarcan A. ve ark. Hayatın Illk Yılında Demir Profilaksisi ve Anemi. Çocuk Sağ. ve Hast. Dergisi 2007; 50: 121581-64 